\title{
Exploring the Students' Behavior Intentions to Adopt E-Learning Technology: A Survey Study Based on COVID-19 Crisis
}

\author{
Arshed Fouad Altameemi ${ }^{1} \&$ Zaher Abdel Fattah Al-Slehat ${ }^{2}$ \\ ${ }^{1}$ Al Buraimi University College, Business Administration, and Accounting, Oman \\ ${ }^{2}$ Tafila Technical University, Business Faculty, Department of Business Economic, Jordan \\ Correspondence: Arshed Altameemi, Al Buraimi University College, Business Administration, and Accounting. \\ AlBuraimi, Oman. E-mail: altameemiarshed@gmail.com
}

Received: March 2, 2021

doi:10.5539/ijbm.v16n6p31

\author{
Accepted: April 4, 2021 \\ Online Published: May 1, 2021 \\ URL: https://doi.org/10.5539/ijbm.v16n6p31
}

\begin{abstract}
E-learning technology adoption has become, during the COVID-19 pandemic, an essential requirement and a new trend to manage the academic activities in the universities which follow traditional education (Face-to-Face Classroom). Because of the significant effect of coronavirus pandemic on the educational Process, this study's primary purpose is to gain an insight into the factors affecting the students' acceptance and their intentions to adopt an e-learning system in the faculty of business at Tafila university in Jordan. A total number of 257 students with different college disciplinary took part in the study by engaging via a survey distributed as a link by WhatsApp, E-mail, and Thuraya Platform. The study formulated a model based on a UTAUT of (Venkatesh et al., 2003) and suggested a new two moderating factors (study qualification level and scientific disciplinary) after drop two variables from the original model to make the model applicable in the context of a study. The data collection analyzed by smart PLS revealed that the research model constructs have positive explanatory power of the student's behavioral intention to adopt an e-learning system and improved after the moderating effect. Final result Sof this study states that the scientific discipline is a critical moderating factor that moderated the behavioral intentions to adopt e-learning technology from Tafila university students' viewpoint and accepted the new situation of academic activities with behavioral intentions to adopt e-learning.
\end{abstract}

Keywords: E-learning technology, UTAUT model, Study qualification level, Scientific disciplinary, and COVID-19

\section{Introduction}

The COVID-19 pandemic poses a significant challenge to manage the education process, whether theoretical or/and practical nature (Ratten \& Jones, 2020). It has been a surprise shock, especially to the traditional education institutions, due to the availability of the infrastructure for e-learning systems and their compatibility with academic and students' needs. Besides that, this pandemic made the e-learning system a critical requirement for completing academic and educational activities at all educational institutions and those that adopt traditional teaching and learning (face-to-face classroom). Despite the obstacles and problems that face transforming the electronic system, the academic activities adaptation with the new trends of COVID-19 become necessary mater to mitigate this crisis's effect. Although in many cases, the transformation may not meet the content of the academic needs, especially those that need practical workshops or quantitative and mathematical processes that are difficult to deal with distance, even if they are subject to blended learning.

The study's theoretical and practical objectives are to diagnose and evaluate the factors affecting students' acceptance of e-learning technology at Tafila university in Jordan and explore their behavioral intentions in adopting e-learning within and after the current situation of a pandemic. The unified theory of acceptance and technology (UTAUT) is used due to its the most popular model to study technology acceptance. It focuses on the technology factors for IT's successful implementation (ALMaiah et al., 2019). Besides that, many citations to the original paper introduced the theory evidence (Venkatish et al., 2016), which stated that the behavioral intent is a construct recommended by previous studies related to e-learning models (Ifinedo et al., 2018). Besides, this model can be used for individual behavior determination in the context of electronic commerce (Venkatish et al., 2012) (Salloum et al., 2019). Based on these objectives, this study is expected to provide a theoretical and 
practical contribution related to the acceptance of e-learning technology under the conditions of COVID-19 in the business faculties.

\section{Conceptual Framework and Literature Review}

Information technology plays a vital role in e-learning environments and a critical enabler and effective way to manage change (Liu et al., 2017). Therefore, e-learning has rapid growth to support students' active academic across the techniques and applications that meet all education needs. E-learning means delivered course materials over the Internet or Intranet (Punnoose, 2012). E-learning encompasses a range of activities such as information communication technologies (ICTs) in supporting learning and teaching, blended learning, and acquiring skills and knowledge entirely by using the internet (Budu et al., 2018). Therefore, all e-learning Platforms represent a new additional knowledge of the higher education institutions; they are systems based on formal learning with electronic resources' assistance (Yu \& Jo, 2014). Spanjers and his colleagues (2015) define e-learning as distance education to reduce classroom time and maximize the benefit of the education process and content enjoyment. It is an opportunity to manage academic and educational activities (Hone \& EI Said, 2016). It is suitable for higher education students, especially those with experience in using technology that meets their needs (Tawafak et al., 2020). Sholihin and his colleagues (2020) stated virtual-reality-based media make the learning process motivating, enjoyable and increases perceived learning effectiveness and the level of ethical efficiency of individuals by increasing their self-efficacy. The e-learning process's success depends on critical factors in online delivery: technology, the instructor, and the previous use of technology from a student's perspective (Volery \& Lord, 2000). Costa and Silva (2010) stated three fundamental pillars: the ease of delivery course material content, the student, and the essential part of the system. In other words, e-learning systems need effective communication channels and innovative methods to measure academic activities' effectiveness, ensuring students' motivation to accept the e-learning system and motivate their behavioral intentions to adopt it.

Based on the above concepts, there are many studies conducted in this field; Chen (2011) showed that both technological expectancy and educational compatibility are essential determinants of e-learning acceptance. Still, the academic compatibility reveals a more significant total effect on e-learning acceptance than four constructs. Adwan and Smedley (2013) concluded that the TAM model could be employed as a practical, theoretical base to predict users' intentions to use e-learning. Abubakar and Ahmad (2015) confirmed that Performance Expectancy, Social Influence, and Facilitating Conditions have a significant positive relationship with BI to use technology and moderated by technology awareness. Evans and Roux (2015) found UTAUT proved more successful in its predictive accuracy of the constructs model of the student's behavioral intention to adopt the e-learning system. Koc and his colleagues (2016) showed an influential exogenous role of context and a strong positive relationship among perceived ease of use, perceived usefulness, trust to e-learning, and Chauhan and Jaiswal (2016) conform of the more robust connection for females. Whereas Lakhal \& Khechin (2016) revealed that performance expectancy and social influence positively impact behavioral intentions, Omerogbe and others (2017) show that Attitude, Social Influence, and technology culturation are healthily determining factors for adopting an e-learning management system. Wu and Chen (2017) mentioned that the perceived usefulness and ease of use of e-learning systems significantly affect students' behavioral intentions in the continuity of using the system and indicate teacher's and student's motivation to obtain the system's benefits.

Salloum and Khaled (2018) mentioned that social influence, performance expectancy, and facilitating conditions important impacted behavioral intentions to use e-learning and led to a successful e-learning system. Sutherland and his colleagues (2019) confirmed that the lectures and seminars involving direct student-teacher contact time are the most important determinant of satisfaction. Meskhi and others (2019) mentioned that the efficiency of e-learning in higher inclusive education depends on the systemic institutional environment, which formed both at the level of the state and the level of a particular university. Garone and others (2019) investigated the university teaching staff's technology acceptance profiles using the UTAUT predictor variables as clustering variables. This model will facilitate decision-making and guidelines for the design of institution-wide professional development initiatives targeted towards the needs of specific groups of university teaching staff. Abusalim his colleagues (2020) stated that student satisfaction with blended learning is related to the teacher training and IT infrastructure for blended learning strategies. Welch and colleagues (2020) noted that the UTAUT model constructs are significant determinants of behavioral intention to use Mobile Learning and found age and gender moderate the relationship between the UTAUT constructs. Han and Conti (2020) concluded that UTAUT and PAM models' emerge constructs could predict and explain social telepresence robots' acceptance in social contexts. Therefore, computer self-efficacy has a positive impact on perceived ease of use (PEOU), but (PEOU) has no significant effect on students' attitudes (Ho et al. 2020). The current study benefits from the cognitive contributions of prior studies to enrich the conceptual and practical framework of the study to analyze the students' behavior intention 
to adopt distance learning technology; besides that, this study is distinct from the previous works because it's done in light of the coronavirus pandemic.

\section{Methodology and Model Specification}

\subsection{Statement of Problem}

Ratten and Jones (2020) confirmed that because of the COVID 19, a greater need now more than ever to embed an entrepreneurial spirit in the education sector and help focus on the positive benefits of finding solutions for the pandemic crisis. Nicola et al. (2020) mentioned that the COVID-19 pandemic could transform management education, and realize this potential management education needs to evaluate its epistemological foundation to challenge existing paradigms critically. COVID-19 crisis imposed an exceptional situation on all traditional education sector institutions, general, and higher education in specific, disrupting face-to-face learning and shifting to distance learning. This transformation has generated a problem of academic educational activities in most public and private universities regarding the adapt their activities to the new situation of e-learning, in light of the absence of other options to complete the academic year requirements. There are obstacles to harmonizing the content and context of educational resources and e-learning platforms' diversity. The needs training programs to develop and improve communication effectiveness between the faculty's members and students in the business faculty's disciplinaries. Based on that, this study tries to answer two questions that were formulated, as follows:

1- What are the determinants of student's acceptance of e-learning technology at Tafila university?

2- Does gender, age, study qualification level, and scientific disciplinary have a moderating effect on the factors that determine students' behavior intentions of Tafila university to adopt e-learning?

\subsection{Model Specification of Study}

To answer the study questions and understanding students' behavioral intentions for adopting e-learning technology, the unified theory of technology acceptance and use (UTAUT) presented by Venkatesh et al. (2003) is the most comprehensive as it serves as a base-line model and has been applied to the study of a variety of technologies related to the acceptance and use of technology (Venkatish et al., 2012). The UTAUT model includes a combination of four constructs nominated from eight models of e-learning technology acceptance and behavioral intent to adopt it (TAM, TAM2, IDT, TPB, TRA, TM, SCT, and Combined TAM \& TPB), these are Performance Expectancy (PE), Efforts Expectancy (EE), Social Influence (SI), and Facilitating Conditions (FC) (Welch et al., 2020). Based on the theoretical background of the unified theory of acceptance and use of technology (UTAUT) and the previous discussion, the researchers made some modifications to the model regarding the moderating factors shown in figure 1. The current study model dropped experience and voluntariness as a moderating variable and replaced them with qualification level and scientific disciplinary. This modification is necessary to make the theory model applicable in the content and context of the COIVD 19 situation and health procedures that do not permit all Jordan universities to continue with traditional education. Thus, the voluntariness variable of using the e-learning system is inapplicable due to the student behaviors are not voluntary to use this system. It replaced the experience variable due to the study's focus to survey the business faculty's scientific disciplinaries that consider technology as assistant tools. So, there will not be variance in the voluntariness and experience variables between students.

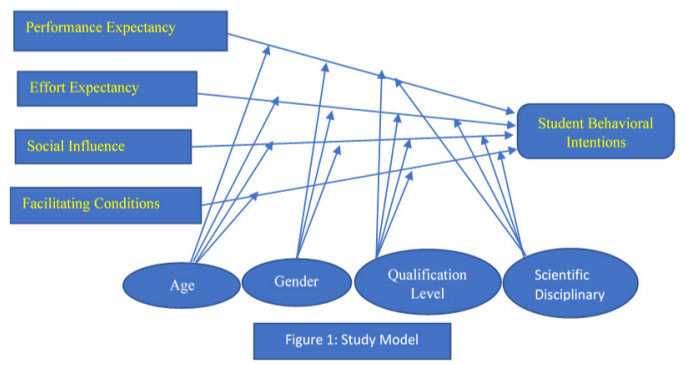

\subsection{Hypotheses of the Study}

Based on the study model, formulating the following hypothesizes:

$\mathrm{H}_{1}$ : Impact of performance expectancy on student's behavioral intention to adopt e-Learning technology will be moderated by gender, age, study qualification level, and scientific disciplinary.

$\mathrm{H}_{2}$ impact of effort expectancy on students' behavioral intention to adopt e-Learning technology will be 
moderated by gender, age, study qualification level, and scientific disciplinary.

H3 impact of social influence on students' behavioral intention to adopt e-Learning technology will be moderated by gender, age, study qualification level, and scientific disciplinary.

$\mathrm{H}_{4}$ Impact of Facilitating conditions on students' behavioral intention to adopt e-Learning technology will be moderated by age, scientific disciplinary, and study qualification.

\subsection{Population and Study Sample}

The study population consisted of all students of business colleges in the Jordanian government universities of the southern region of the Hashemite Kingdom of Jordan, which three universities. The study sample was chosen based on the facilitated sample method and consisted of the College of Business students, Tafila Technical University.

\subsection{Data Collection}

Questionnaires were designed to the five-point Likert scale and included (30) questions concerning the study model's constructs. It is subjected to refereeing by academic experts to verify its scientific integrity and was modified according to their observations. Engaged Participants were via an online Google survey distributed as a link by students' e-mail, WhatsApp, and Thuraya Platform of the university, which considers the survey sampling with obligation answers with $\left({ }^{*}\right)$ in each question. The study was distributed (300) questionnaire, (270) retrieved, and (14) were excluded due to invalid for analysis. Consequently, the valid questionnaires to analysis became (256) with (94\%) of the retrieved questionnaires. Table (1) shows the study sample's demographic characteristics regarding (gender, age, academic level, the student's academic year, and scientific disciplinary).

Table 1. Demographic characteristics of the study sample

\begin{tabular}{llll}
\hline & Category & Frequency & Percentage \\
\hline Gender & Male & 96 & 37.5 \\
& Female & 160 & 62.5 \\
Age & Total & 256 & $\% 100$ \\
& Less than 20 years & 35 & 13.7 \\
& $20-24$ years & 172 & 67.2 \\
& $25-29$ years & 35 & 13.7 \\
& More than 30 years & 14 & 5.5 \\
Study qualification level & Total & 256 & $\% 100$ \\
(SQL) & Diploma & 26 & 10.2 \\
& Bachelor & 204 & 79.7 \\
Student's level & Master & 26 & 10.2 \\
& Total & 256 & $\% 100$ \\
& First-year & 31 & 12.1 \\
& Second-year & 82 & 32 \\
Scientific Disciplinary & Third-year & 96 & 37.5 \\
(SD) & Fourth-year & 47 & 18.4 \\
& Total & 256 & $\% 100$ \\
& Banking and financial sciences & 85 & 33.2 \\
& Business economy & 10 & 3.9 \\
& Business management & 83 & 32.4 \\
& Accounting & 78 & 30.5 \\
& Total & 256 & $\% 100$ \\
\hline
\end{tabular}

Sources: Smart PLS Output.

\subsection{Validity and Reliability}

Table 2 shows Cronbach Alpha (CA), Composite Reliability (CR), Average Variance Extracted (AVE), and Multicollinearity to check the questionnaire validity and reliability. Cronbach Alpha's result is acceptable due to greater than (0.70), and there is a high degree of internal consistency of the questionnaire content (Hair et al., 2010; Sekaran \& Bougie, 2009). Tested The composite reliability coefficient was to verify the validity of internal consistency. Its value ranges $(0-1)$, and its value is acceptable whenever greater than $(0.70)$. Besides that, the average values of the interpreted average variance (AVE) were within the acceptable limits, and the (AVE) value is proper when exceeds $(0.50)$. There is no multicollinearity problem among the independent study 
variables due to the Tolerance values were more significant than 0.2 and all VIF values less than five within the permissible limits.

Table 2. Validity and reliability of the questionnaire

\begin{tabular}{llllll}
\hline Factor & CA & CR & AVE & Tolerance & VIF \\
\hline Performance Expectancy & 0.888 & 0.915 & 0.643 & 0.279 & 3.588 \\
Effort Expectancy & 0.919 & 0.936 & 0.711 & 0.328 & 3.046 \\
Social Influence & 0.875 & 0.906 & 0.621 & 0.377 & 2.649 \\
Facilitating Conditions & 0.912 & 0.932 & 0.694 & 0.334 & 2.990 \\
Student Behavioral Intentions & 0.931 & 0.946 & 0.747 & - & - \\
\hline
\end{tabular}

Sources: Smart PLS Output.

\subsection{Operational Definition of Variables Scale}

The study model has used the four constructs of the UTAUT model to adapt to the current study operational framework and formulate the scales consistent with the study goal. Table 3 explains the variable scales based on previous studies (Venkatesh et al., 2003, 460).

Table 3. Constructs and scales of study model

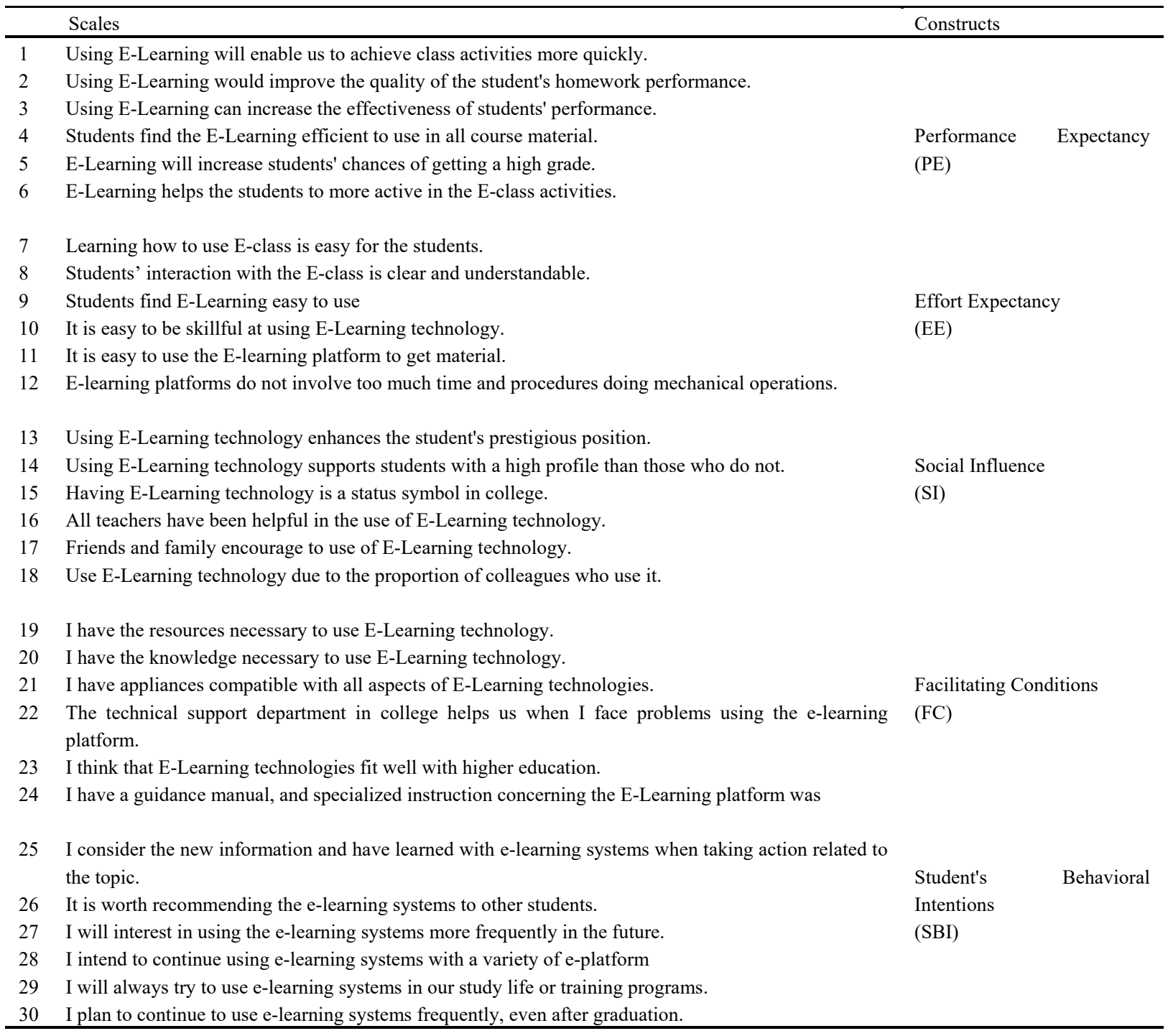




\section{Discussion}

\subsection{Factors Loading Analysis}

The values of the arithmetic averages of respondents were used as a criterion to determine the level of the response (means description: $1-2.33$ low, moderate $2.34-3.67$, and high $3.68-5$ ). Table 4 indicates that the response level within moderate except scales (4) of performance expectancy is low. This result shows the respondents' convergence regarding their acceptance and intentions to use e-learning technology. Whereas the factor loading results of all component constructs are within acceptable limits (more than $(0,70)$, except scale (16) of a social influence construct was less than standard, so excluded from level analysis, as shown in the following Figure 2. Factor Loading results confirm that the constructs scales affect the student's acceptance of e-learning technology and behavioral intention to use this system.

Table 4. Mean, standard deviations, and factor loadings

\begin{tabular}{llllll}
\hline Constructs Model & Scale & Mean & SD & Level & Factor Loading \\
\hline & 1 & 3.17 & 1.231 & moderate & 0.756 \\
Performance Expectancy & 2 & 2.87 & 1.230 & moderate & 0.839 \\
(PE) & 3 & 2.37 & 1.226 & moderate & 0.725 \\
& 4 & 2.17 & 1.081 & low & 0.790 \\
& 5 & 2.79 & 1.169 & moderate & 0.885 \\
& 6 & 2.68 & 1.160 & moderate & 0.807 \\
& 7 & 2.77 & 1.088 & moderate & 0.860 \\
Effort Expectancy & 8 & 2.81 & 1.194 & moderate & 0.854 \\
(EE) & 9 & 2.76 & 1.145 & moderate & 0.827 \\
& 10 & 2.47 & 1.048 & moderate & 0.884 \\
& 11 & 2.67 & 1.075 & moderate & 0.857 \\
Social Influence & 12 & 2.80 & 1.170 & moderate & 0.817 \\
(SI) & 13 & 2.82 & 1.045 & moderate & 0.896 \\
& 14 & 2.97 & 1.073 & moderate & 0.839 \\
& 15 & 2.46 & 0.982 & moderate & 0.809 \\
& 16 & 2.55 & 1.105 & moderate & 0.574 \\
& 17 & 2.58 & 1.169 & moderate & 0.699 \\
Facilitating Conditions & 18 & 2.92 & 1.162 & moderate & 0.866 \\
(FC) & 19 & 3.00 & 1.243 & moderate & 0.826 \\
& 20 & 2.52 & 1.033 & moderate & 0.763 \\
& 21 & 2.82 & 1.165 & moderate & 0.858 \\
Student's Behavioral Intention & 22 & 2.98 & 1.161 & moderate & 0.839 \\
(SBI) & 27 & 2.73 & 1.117 & moderate & 0.909 \\
& 28 & 2.79 & 1.153 & moderate & 0.902 \\
& 29 & 2.71 & 1.097 & moderate & 0.905 \\
& 30 & 2.67 & 1.195 & moderate & 0.843 \\
\hline & 24 & 2.73 & 1.192 & moderate & 0.840 \\
& 25 & 2.43 & 0.959 & moderate & 0.870 \\
& & & & & \\
& 26 & & & \\
& 2.77 & 1.196 & moderate & 0.749 \\
& & & & \\
& 23 & &
\end{tabular}

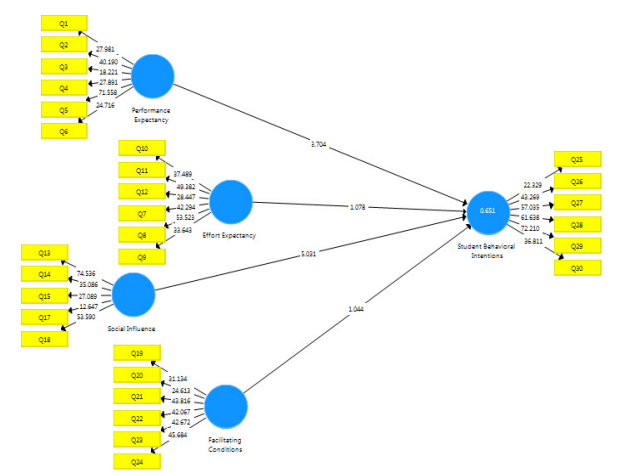

Figure 2. Standardized loading and path coefficient for the trimmed model 


\subsection{Test Hypotheses}

\subsubsection{Analysis of First Hypotheses Testing Results}

Table (5) shows the testing results of the first hypothesis before and after the effect of a modified variable. The impact of performance expectancy has a positive explanatory power $\left(\mathrm{R}^{2}, 57.3 \%\right)$ for students' behavioral intention to adopt the e-learning system. This effect is statistically significant at $(0.05)$ based on the T-test. Moreover, after moderated the effect by modified variables, the explanatory power increased to (62\%) by the influence of level and scientific discipline. Whereas age and gender failed to moderate the effect, they had no relationship with students' behavioral intentions to adopt e-learning technology. Therefore, the first hypothesis is accepted.

Table 5. First hypotheses testing result

\begin{tabular}{|c|c|c|c|c|c|c|c|c|c|c|c|}
\hline \multirow{3}{*}{$\begin{array}{l}\text { Dependent } \\
\text { Variable }\end{array}$} & \multirow{3}{*}{$\begin{array}{l}\text { Independent } \\
\text { Variables } \\
\text { PE }\end{array}$} & \multicolumn{5}{|c|}{ Before the Moderating Effect } & \multicolumn{5}{|c|}{ After the Moderating Effect } \\
\hline & & \multicolumn{2}{|c|}{ B SD } & T-test & Sig & Result & \multirow[b]{2}{*}{ B } & \multirow[b]{2}{*}{ SD } & \multirow[b]{2}{*}{ T-test } & \multirow[b]{2}{*}{ Sig } & \multirow[b]{2}{*}{ Result } \\
\hline & & 0.76 & 0.03 & 25.1 & 0.000 & Acce. & & & & & \\
\hline & $\mathrm{PE}$ & & & & & & 0.751 & 0.036 & 21.11 & 0.000 & Acce. \\
\hline & Age & & & & & & -0.027 & 0.059 & 0.456 & 0.649 & Rej. \\
\hline \multirow{5}{*}{ SBI } & Gender & & & & & & 0.071 & 0.044 & 1.603 & 0.110 & Rej. \\
\hline & SQL & & & & & & -0.213 & 0.065 & 3.289 & 0.001 & Acce. \\
\hline & S. Disciplinary & & & & & & -0.086 & 0.036 & 2.365 & 0.018 & Acce. \\
\hline & $\mathrm{R}^{2}$ & 0.573 & & & & & 0.622 & & & & \\
\hline & $\mathrm{R}^{2}$ Adjusted & 0.571 & & & & & 0.608 & & & & \\
\hline
\end{tabular}

\subsubsection{Analysis of Second Hypotheses Testing Results}

Table 6 shows the second hypothesis testing results before and after a modified variable's effect. The effect of effort expectancy has a positive explanatory power $\left(\mathrm{R}^{2}, 45.8 \%\right)$ for students' behavioral intention to adopt the e-learning system. This effect is statistically significant at $(0.05)$ based on the T-test. Furthermore, after moderated the effect by modified variables, the explanatory power increased up to $(50 \%)$ by gender and scientific discipline. Whereas age and study qualification level failed to moderate the effect, they had no relationship with students' behavioral intentions to adopt the e-learning technology regarding the effort expectancy. Therefore, the second hypothesis is accepted.

Table 6. Second hypotheses testing result

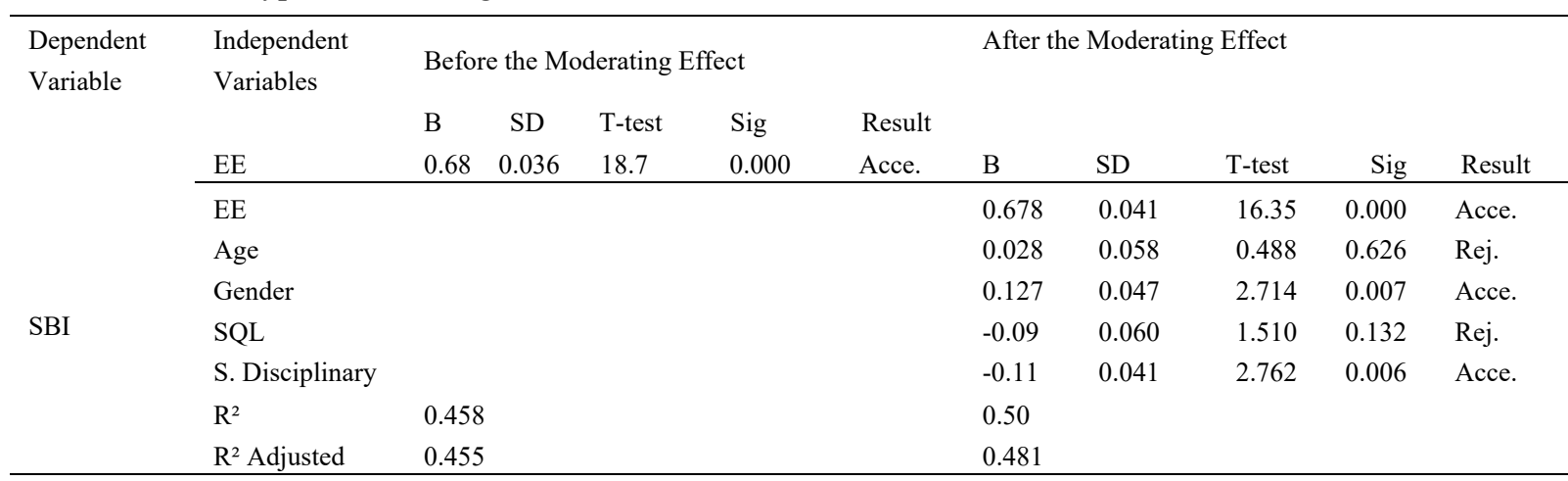

\subsubsection{Analysis of Third Hypotheses Testing Results}

Table 7 shows the third hypothesis testing results before and after a modified variable effect. Social influence has a positive explanatory power $\left(\mathrm{R}^{2} 58.3 \%\right)$ for students' behavioral intention to adopt the e-learning system. This effect is statistically significant at $(0.05)$ based on the T-test. After moderated the effect by modified variables, 
the explanatory power increased to (61.1\%) by the impact of a scientific discipline. Whereas age, gender, and level failed to moderate the effect, they had no relationship with students' behavioral intentions to adopt e-learning technology. Therefore, the third hypothesis is accepted.

Table 7. Third hypotheses testing result

\begin{tabular}{|c|c|c|c|c|c|c|c|c|c|c|c|}
\hline \multirow[t]{2}{*}{$\begin{array}{l}\text { Dependent } \\
\text { Variable }\end{array}$} & \multirow{3}{*}{$\begin{array}{l}\text { Independent } \\
\text { Variables } \\
\text { SI }\end{array}$} & \multicolumn{5}{|c|}{ Before the Moderating Effect } & \multicolumn{5}{|c|}{ After the Moderating Effect } \\
\hline & & B & SD & T-test & Sig & Result & & & & & \\
\hline \multirow{8}{*}{ SBI } & & 0.763 & 0.30 & 25.87 & 0.000 & Acce. & $\mathrm{B}$ & SD & T-test & Sig & Resul \\
\hline & SI & & & & & & 0.787 & 0.039 & 20.05 & 0.000 & Acce. \\
\hline & 40 & & & & & & 0.09 & 0.078 & 1.149 & 0.251 & Rej. \\
\hline & Age & & & & & & 0.1 & 0.049 & 0.988 & 0.323 & Rej. \\
\hline & Gender & & & & & & -0.1 & 0.065 & 1.583 & 0.114 & Rej. \\
\hline & $\begin{array}{l}\text { SQL } \\
\text { S. Disciplinary }\end{array}$ & & & & & & -0.11 & 0.048 & 2.245 & 0.025 & Acce. \\
\hline & $\mathrm{R}^{2}$ & 0.583 & & & & & 0.611 & & & & \\
\hline & $\mathrm{R}^{2}$ Adjusted & 0.581 & & & & & 0.597 & & & & \\
\hline
\end{tabular}

\subsubsection{Analysis of Fourth Hypotheses Testing Results}

Table (8) shows the fourth hypothesis testing results before and after a modified variable effect. The study excluded the gender-modified variable from testing because conditions are available to all students regardless of gender. The facilitating conditions have positive explanatory power $\left(\mathrm{R}^{2} 46.2 \%\right)$ for students' behavioral intention to adopt the e-learning system. This effect is statistically significant at $(0.05)$ based on the T-test. After moderated the effect by modified variables, the explanatory power increased to (47.9\%) by the impact of age and study qualification level. Whereas scientific discipline failed to moderate the effect, it was no relationship with students' behavioral intentions to adopt e-learning technology. So, the fourth hypothesis is accepted.

Table 8. Fourth hypotheses testing result

\begin{tabular}{|c|c|c|c|c|c|c|c|c|c|c|c|}
\hline \multirow{6}{*}{$\begin{array}{l}\text { Dependent } \\
\text { Variable }\end{array}$} & & \multirow{2}{*}{\multicolumn{5}{|c|}{ Before the Moderating Effect }} & \multirow{2}{*}{\multicolumn{5}{|c|}{ After the Moderating Effect }} \\
\hline & \multirow{2}{*}{$\begin{array}{l}\text { Independent } \\
\text { Variables } \\
\text { FC }\end{array}$} & & & & & & & & & & \\
\hline & & 0.68 & 0.036 & 18.99 & 0.000 & Acce. & B & SD & T-test & Sig & Result \\
\hline & $\mathrm{FC}$ & & & & & & 0.684 & 0.036 & 17.402 & 0.000 & Acce. \\
\hline & Age & & & & & & 0.117 & 0.056 & 2.07 & 0.039 & Acce. \\
\hline & SQL & & & & & & -0.112 & 0.042 & 2.691 & 0.007 & Acce. \\
\hline SBI & S. Disciplinary & & & & & & -.065 & 0.053 & 1.216 & 0.225 & Rej. \\
\hline & $\mathrm{R}^{2}$ & 0.462 & & & & & 0.479 & & & & \\
\hline & $\mathrm{R}^{2}$ Adjusted & 0.460 & & & & & 0.464 & & & & \\
\hline
\end{tabular}

\section{Conclusion Remarks}

The study established an extended UTAUT by incorporating new modified variables regarding the study qualification level and scientific disciplinary to provide significant contributions to the research of E-learning systems acceptance and behavioral intention in higher education. The findings of the study revealed the following conclusions: -

- All study model constructs have an average level and explain that these constructs affect students' acceptance of e-learning technology and positive behavioral intention toward this system. This result consistent with the conceptual framework of the UTAUT model and with the study result of Evans \& Roux (2015), Welch et al. (2020), and Abubakar and Ahmad (2015).

- The first hypothesis has shown a positive effect of the expected performance on students' behavioral intentions to adopt e-learning technology. This system will increase their effort to perform academic and 
educational activities and support students' qualifications and scientific disciplinary. This result disagrees with the original conceptualization of UTAUT regarding age and gender as modifier variables and with Chauhan \& Jaiswal (2016).

- The second hypothesis has shown that the study sample has perceived that the e-learning system does not need special academic and educational activities. Gender and scientific discipline play a vital role in moderating students' behavioral intentions to adopt e-learning, regardless of the study qualification. It is consistent and in harmony with the numerous prior studies regarding the use of e-learning technologies (Adwan \& Smedley 2013, \& Koc et al., 2016) (Wu \& Chen, 2017) suggested the scientific study model disciplinary.

- The third hypothesis has shown that the study sample effects by others' beliefs (family, friends) to use e-learning technology acceptance and agree with Khechin's (2016) study. Here, scientific specialization plays a vital role in exploring students' behavioral intentions to use the e-learning system. Whereas age, gender, and study qualification level were not.

- The fourth hypothesis result stated that it is appropriate to provide reasonable facilities to the students that comply with gender and age (agree with Abusalim et al., 2020). Facilities have a negative correlation with study qualification level regardless of scientific specialization.

- Based on those as mentioned above, it can be said that scientific disciplinary is a critical moderating factor of the behavioral intentions of the students to adopt e-learning technology from the viewpoint of Tafila university students. It plays a vital role in mediating three constructs of the study model; there are performance expectancy, effort expectancy, and social influence. In general, they have accepted the new situation of academic activities with behavioral intentions to adopt e-learning.

\section{Limitations and Future Research Directions}

Although this study added a significant contribution regarding the students' behavior intentions literature and its relation to adopting e-learning, some limitations need to be considered:

1. The data collection was constrained to the faculty of business the Tafila University. Therefore, caution is required when generalizing the study results to other faculties and other universities in Jordan.

2. The study used the facilitated sampling technique for data collection due to COVID 19 conditions, limiting the study findings' generalization.

3. Thus, further comprehensive study surveys should be regarding future directions of the students' behaviour intentions after the COVID 19 pandemic.

\section{References}

Abubakar, F. M., \& Ahmad, H. B. (2015). Empirical Investigation of Moderating Effect of Technology Awareness in UTAUT. Nigerian Journal of Management Technology and Development, 109-134.

Abusalim, N., Rayyan, M., Jarrah, M., \& Sharab, M. (2020). Institutional adoption of blended learning on a budget. The International Journal of Educational Management, 34(7), 1203-1220.

Adwan, A., \& Smedley, J. (2013). Exploring students' acceptance of e-learning using Technology Acceptance Model in Jordanian universities. International Journal of Education and Development using Information and Communication Technology, 9(2), 4-18.

ALMaiah, M. A., ALAmri, M. M., \& AL-Rahmi, W. (2019). Applying the UTAUT Model to Explain the Students' Acceptance of Mobile Learning System in Higher Education, IEEE Access, 7, 174673-174686.

Budu, K., W., Yinping, M., \& Mireku, K. K. (2018). Investigating the Effect of Behavioral Intention on E-learning Systems Usage: Empirical Study on Tertiary Education Institutions in Ghana. Mediterranean Journal of Social Sciences, 9(3), 201-216.

Chauhan, S., \& Jaiswal, M. (2016). Determinants of acceptance of ERP software training in business schools: Empirical investigation using the UTAUT model. The International Journal of Management Education, 14(3), 248-262. https://doi.org/10.1016/j.ijme.2016.05.005

Chen, J. (2011). The effects of education compatibility and technological expectancy on e-learning acceptance, Computers \& Education an International Journal, 57(2), 1501-1511. https://doi.org/10.1016/j.compedu.2011.02.009

Costa, G. J. M., \& Silva, N. S. A. (2010). Knowledge versus content in e-learning: A philosophical discussion. Information Systems Frontiers, 12(4), 399-413. 
Evans, N. D., \& Roux, J. I. (2015). Modeling the acceptance and use of electronic learning at the University of Zululand. South Africa Journal of Libraries and Information Science, 81(2), 26-38. https://doi.org/10.7553/81-2-1562

Garone, A., Pynoo, B., Tondeur, J., Cocquyt, C., Vanslambrouck, S., Bruggeman, B., \& Struyven, K. (2019). Clustering university teaching staff through UTAUT: Implications for accepting a new learning management system. British Journal of Educational Technology, 50(5), 2466-2483. https://doi.org/10.1111/bjet.12867

Hair, J., Black, W., Babin, B., \& Anderson, R. (2010). Multivariate Data Analysis: A Global Perspective (7th ed.). Pearson Education, Inc., Saddle River, New Jersey.

Han, J., \& Conti, D. (2020). The Use of UTAUT and Post Acceptance Models to Investigate the Attitude towards a Telepresence Robot in an Educational Setting, Robotics, 19(2), 2-19. https://doi.org/10.3390/robotics9020034

Ho, N. T. T., Sivapalan, S., Pham, H. H., Nguyen, L. T. M., Pham, A. T. V., \& Dinh, H. V. (2020). Students' adoption of e-learning in an emergency: the case of a Vietnamese university during COVID-19. Interactive Technology and Smart Education.

Hone, K. S., \& El Said, G. R. (2016). Exploring the factors affecting MOOC retention: A survey study. Computers \& Education, 98, 157-168

Ifinedo, P., Pyke, J., \& Anwar, A. (2018). Business undergraduates' perceived use outcomes of Thuraya in a blended learning environment: The roles of usability factors and external support. Telematics and Informatics, 35(1), 93-102.

Koç, T., Turana, A. H., \& Okursoyb, A. (2016). Acceptance and usage of a mobile information system in higher education: An empirical study with structural equation modeling. The International Journal of Management Education, 14(3), 286-300. https://doi.org/10.1016/j.ijme.2016.06.001

Lakhal, S., \& Khechine, H. (2016). Student intention to use desktop web-conferencing according to course delivery modes in higher education. The International Journal of Management Education, 14(2), 146-160

Liu, Y., Shankar, V., \& Yun, W. (2017). Crisis management strategies and the long-term effects of product recalls on firm value. Journal of Marketing, 18(5), 30-48. https://doi.org/10.1509/jm.15.0535

Meskhi, B., Ponomareva, S., \& Ugnich, E. (2019). E-learning in higher inclusive education: needs, opportunities, and limitations. The International Journal of Educational Management, 33(3), 424-437. https://doi.org/10.1108/IJEM-09-2018-0282

Nicola, M., Alsafi, Z., Sohrabi, C., Kerwan, A., Al-Jabir, A., Iosifidis, C., Agha, M., \& Agha, R. (2020). The socio-economic implications of the coronavirus pandemic (COVID-19): A review. International Journal of Surgery, 78(1), 185-193.

Omerogbe, N. A., Azeta, A., Chiazor, I. A., \& Omoregbe, S. O. (2017). Predicting the Adoption of E-learning Management System: A Case of Selected Private Universities in Nigeria. Turkish Online Journal of Distance Education-TOJDE, 18(2), 106-121. https://doi.org/10.17718/tojde.306563

Punnoose, A. C. (2012). Determinants of Intention to Use eLearning Based on the Technology Acceptance Model. Journal of Information Technology Education: Research, 11, 301-337.

Ratten, V., \& Jones, P. (2020). Covid-19 and entrepreneurship education: Implications for advancing research and practice. The International Journal of Management Education.

Salloum, S. A., \& Shaalan, K. (2018). Factors Affecting Students' Acceptance of E-Learning System in Higher Education Using UTAUT and Structural Equation Modeling Approaches. International Conference on Advanced Intelligent Systems and Informatics, 469-480. https://doi.org/10.1007/978-3-319-99010-1_43

Salloum, S. A., Al-Emran, M., Khalaf, R., Habes, M., \& Khaled, S. (2019). An Innovative Study of E-Payment Systems Adoption in Higher Education: Theoretical Constructs and Empirical Analysis. International Journal of Interactive Mobile Technologies, 13(6), 68-83. https://doi.org/10.3991/ijim.v13i06.9875

Sekaran, U., \& Bougie, R. (2009). Research methods for business: A skill-building approach (5th ed.). New York, NY: John Wiley \& Sons INC.

Sholihin, M., Sari, R. C., Yuniarti, N. C., \& Ilyana, S. (2020). A new way of teaching business ethics: The evaluation of virtual reality-based learning media. The International Journal of Management Education, 
18(3). https://doi.org/10.1016/j.ijme.2020.100428.

Spanjers, I. A. E., Könings, D. K., Leppink, J., Verstegen, D. M. L., Jong, N. D, Czabanowska, K., \& Van Merrienboer, J. J. (2015). The promised land of blended learning: Quizzes as a moderator. Educational Research Review, 15, 59-74

Sutherland, D., Warwick, P., \& Anderson, J. (2019). What factors influence student satisfaction with module quality? A comparative analysis in a UK business school context. The International Journal of Management Education, 17(3), 100312. https://doi.org/10.1016/j.ijme.2019.100312

Tawafak, R. M., Malik, S. I., \& Alfarsi, G. (2020). Development of Framework from Adapted TAM with MOOC Platform for Continuity Intention. Development, 29(1), 1681-1691.

Venkatesh, V., Morris, M. G., Davis, G. B., \& Davis, F. D. (2003). User Acceptance of Information Technology: Toward A Unified View. MIS Quarterly, 17(3), 425-478. https://doi.org/10.2307/30036540

Venkatesh, V., Thong, J. Y. L., \& Xu, X. (2012). Consumer Acceptance and Use of Information Technology: Extending the UTAUT. MIS Quarterly, 36(1), 157-178. https://doi.org/10.2307/41410412

Venkatesh, V., Thong, J. Y. L., \& Xu, X. (2016). Unified Theory of Acceptance and Use of Technology: A Synthesis and the Road Ahead, Journal of the Association for Information Systems, May, 17(5), 328-376. https://doi.org/10.17705/1jais.00428

Volery, T., \& Lord, D. (2000). Critical success factors in online education. The International Journal of Educational Management, 14(5), 216-223. https://doi.org/10.1108/09513540010344731

Welch, R., Alade, T., \& Nichol1, L. (2020). Using the Unified Theory of Acceptance and Use of Technology (UTAUT) model to determine Factors affecting a Mobile Learning adoption in the workplace: A study of the Science Museum Group. IADIS International Journal on Computer Science and Information Systems, 15(1), 85-98. https://doi.org/10.33965/ijcsis_2020150107

Wu, B., \& Chen, X. (2017). Continuance intention to use MOOCs: Integrating the technology acceptance model (TAM) and task technology fit (TTF) model. Computers in Human Behavior, 67, 221-232. https://doi.org/10.1016/j. Chub.2016.10.028

Yu, T., \& Jo, I. H. (2014). Educational technology approach toward learning analytics: Relationship between student online behavior and learning performance in higher education. In Proceedings of the Fourth International Conference on Learning Analytics and Knowledge, 269-270. https://doi.org/10.1145/2567574.2567594

\section{Copyrights}

Copyright for this article is retained by the author(s), with first publication rights granted to the journal.

This is an open-access article distributed under the terms and conditions of the Creative Commons Attribution license (http://creativecommons.org/licenses/by/4.0/). 